\title{
Special Education in Saudi Arabia
}

\author{
Zaed M. Bin Battal \\ College of Education, King Saud University, Riyadh, Saudi Arabia
}

\begin{abstract}
Saudi Arabia is a developing country situated in the southwestern region of Asia. It is the world's largest producer and exporter of oil and its derivatives. The modernization of Saudi Arabia has increased dramatically during the last decades as a result of increasing oil revenues; therefore, it is interesting to examine how special education practices in the kingdom have developed. This paper describes the emergence, development, and present status of Special Education in Saudi Arabia. The scope of this analysis is limited to the efforts of the Ministry of Education, for it is the major service provider. The expansion of services to include nontraditional areas of exceptionalities and service delivery models is discussed. The principle factors contributing to the growth of the field are identified.
\end{abstract}

\section{Introduction}

Before the unification of the Kingdom of Saudi Arabia in 1932, education was limited to a few schools serving a small demographics. Access and affordability was an issue of concern as well. The development of education continued to be slow and fragmented remarkably. This growth is evident in the quantitative increase of schools, students, and teachers. When the Ministry of Education was established, there were approximately 300 schools serving several thousand students mainly in urban areas. Today, there are 47325 schools providing education to nearly five million students, taught by more than 420443 teachers. Furthermore, schools are found in both rural and urban areas [1,2].

A major part of this dramatic growth is the emergence and development of the field of special education. The services of special education in Saudi Arabia have moved from segregated schools to mainstreamed schools. Since the establishment of the Ministry of Education in 1953, the number of schools has increased in Saudi Arabian mainstreaming programs to serve different categories of students with special needs. In addition, the government provides several different opportunities for individuals with disabilities such as monthly academic and living expense compensation, disabilities equipment, free transportation, 50\% reduced air fare, and scholarships granted to the gifted disabled.

In this paper, the development of special education infrastructure is described, from its emergence to the present time, highlighting the efforts of the Ministry of Education and discussing the major reasons for their progress in Special Education. Special education in Saudi Arabia has witnessed remarkable growth due to strategic government support, planning, and the efforts of the General Administration of Special Education within the Ministry of Education. To provide a context for the reader, basic information about Saudi Arabia is given first before the discussion of special education field.

\section{Saudi Arabia}

Saudi Arabia is a large, developing country in the southwestern region of Asia, occupying about $80 \%$ of the Arabian Peninsula with an area of 865,000 square miles. This area is almost equivalent to the United States' area east of the Mississippi [3]. The country is divided into five regions, with the city of Riyadh as the capital. Saudi Arabia is home to Islam's two holy mosques, Al-Masjid al-Haram in Mecca, and Al-Masjid Al-Nabawi in Medina. The nation is bounded by the Arabian Gulf, Qatar, and the United Arab Emirates on the east; on the west by the Red Sea; on the north by Jordan, Iraq, and Kuwait; and on the south by Yemen and Oman (see Figure1).

The land in Saudi Arabia is generally arid with a desert climate. It is similar to the climate in the Southwestern United States with average temperatures of 90 degrees Fahrenheit in the summer and 15 degrees Fahrenheit in the winter. Except the southwestern part (Asir Province), Saudi Arabia receives slight rainfall, about six inches per year [7].

As for the resources, Saudi Arabia is the world's largest producer and exporter of oil, and has one quarter of the world's known oil reserves, that is over 260 billion barrels [8]. The development and modernization of the Kingdom of Saudi Arabia have 


\begin{tabular}{|c|c|c|}
\hline & Population & $30,770,375$ \\
\hline & Government Type_ & Monarchy \\
\hline & Population $0-14$ years $(\%)$ & 27.6 \\
\hline & $\%$ Children enrolled in primary education & 108 \\
\hline & School life expectancy (years) & 16.9 \\
\hline & Primary to secondary transition rate $(\%)$ & 96.3 \\
\hline & Pupil/teacher ratio (primary) & 9.6 \\
\hline & Percentage of repeaters, primary $(\%)$ & 1.4 \\
\hline & Survival Rate to Grade $5(\%)$ & 98.7 \\
\hline & Public expenditure on education: & \\
\hline & as $\%$ of total government expenditure & 17.7 \\
\hline & $\%$ of Literate youth & 99.2 \\
\hline & $\%$ of Literate adults & 94.4 \\
\hline & Poverty Rate: (\% of pop. On less than $\$ 2$ a day) & $\ldots$ \\
\hline & Human Development Index & .80 \\
\hline & Education Index & .72 \\
\hline & Annual population growth rate $(\%)$ & 1.9 \\
\hline & Life Expectancy at birth (years) & 73.9 \\
\hline & Infant mortality rate $(0 / 00)$ & 7 \\
\hline & Date of Signature of UN Convention on the Rights & $6-2008$ \\
\hline se & Of person s with Disabilities & \\
\hline & Of person s with Disabilities & $0-2000$ \\
\hline
\end{tabular}

Figure 1. The maps of the Kingdom of Saudi Arabia Source: (CIA Word Fact Book [4]; UNESCO Institute for Statistics [5]; United Nations [6])

increased dramatically during the last few decades as a result of producing and exporting oil [9].

This product has introduced the country and its people to a new stage. An author described the situation about 30 years ago as follows: "In Saudi Arabia a traditional, conservative Islamic society has suddenly been confronted with the full force of twentieth century western technology and thought" (p. 12) [10].

The population is estimated to be $30,770,375$, with $20,702,536$ people $(67.3$ percent of the population) being Saudi citizens and with 10,067,830 non-citizens. The population growth rate of Saudi Arabia is 2.55 percent. The density is 15.3 persons per square mile [11]. The life expectancy at birth is on average 73.87 years, with males living an average of 71.93 years and females an average of 75.9 years. The Saudi Arabian family has approximately 2.26 children per household and chooses most frequently to live in cities; with $85 \%$ of the total population living in urban areas [9].

\section{Special education in Saudi Arabia}

A little more than half a century ago, the field of special education was virtually unknown to Saudi Arabia. Individuals with special educational needs were absorbed into society by their families and relatives, receiving no formal Special education. Although Islam, the dominant and governing religion in the nation, guarantees them the rights for free, non-discriminatory education, the government was fully occupied with building the infrastructure of the country [12]. It was not until the 1960s that the Ministry of Education was able to formally plan for special education services. The goal was and remains to enhance the quality of life for exceptional people, including the ability to function well in society [13].

Having provided this background information, a discussion of the development of special education in Saudi Arabia follows. For illustration, it is 
appropriate to divide the movement into three stages: the emergence, the development, and the expansion.

\section{The emergence}

The birth of the special education field in Saudi Arabia occurred in 1958 when Saudi citizen (Ahmad Aba Hessain), who was residing in Kuwait at that time, was visiting his hometown and took it upon himself to teach the Braille system to a group of blind individuals, e.g., Mohammed Bin Hussain, Abdulah Al Ganem, Ali Alsoayyd, and Mohammed Almofada [14]. On a personal initiative, some of the blind individuals from this group started teaching Braille to other blind people at their homes. Later on, they sought the government's assistance by contacting the Ministry of Education, which provided the facilities for an evening class at one of the public schools in Riyadh [15].

The first enrollment in the evening class comprised of 100 students who were visually impaired. Most of these students also attended daytime classes in the regular education $[12,15]$. As the reader may note, most of the students who enrolled in the evening class were in regular schools. This is because the education of individual with disabilities, in Saudi Arabia, started through regular schools especially for students with visual impairment, but later, it was transferred to separate special education schools (institutes).

Due to the success of this experience, the Ministry of Education adopted this infant field of special education and opened the first special school in the Kingdom for blind male students in 1960, thus marking the official beginning of special education programming in Saudi Arabia. This was an important landmark for students with visual impairment. This first special school, called Al Nour (The Light) had five elementary classes, three vocational classes, and a total of 40 students [12]. As the number of schools for the blind grew, they have all taken on the name Al Nour in honor of this first institution. Since the beginning of this first school, the growth of special education institutes has been continuous.

Table 1. Brief Historical Landmarks in Special Education in Saudi Arabia

\begin{tabular}{|l|c|}
\hline \multicolumn{1}{|c|}{ Event } & Year \\
\hline Learning Braille system by Saudi blind citizens & 1958 \\
\hline Special Education School for Blind Students & 1960 \\
\hline Administration of Special Education in Ministry of Education & 1964 \\
\hline Special Education School for Deaf Students & 1964 \\
\hline $\begin{array}{l}\text { Special Education School for Students with intellectual } \\
\text { disabilities }\end{array}$ & 1971 \\
\hline First trails of mainstreaming & 1984 \\
\hline Special Education Department at King Saud University & 1984 \\
\hline Graduation of first class of special education teachers & 1988 \\
\hline
\end{tabular}

\section{The development}

In 1962, the Ministry of Education issued a resolution to establish the foundations of the administration of special education, to oversee planning and supervising the new field. As a result of the new administration, new institutions were opened for the first time in the Kingdom (all in Riyadh) in 1964; an institution for blind girls, an institution for deaf girls, and an institution for deaf boys were all opened during this year. The institutions for the deaf were christened Al Amal (The Hope). The schools for the deaf that followed were also named Al Amal in honor of this first school. In 1971, two more institutions were established: one for intellectually disabled males, and another for intellectually disabled females. In 1972, the administration of special education was founded three specialized departments responsible for the education of students who are blind, deaf, or intellectually disabled respectively $[15,16]$.

From that time on, the field of special education has made considerable progress. By 1992, the number of special education institutes reached 47 , providing services to 5,730 students. These institutes include 1,346 teachers, and 334 administrators (see Table 1).

The field of special education in its beginning stage considerate only on the education of students with severe visual impairment, students with severe hearing impairment, and educable students with intellectual disabilities through special schools. These institutions are no longer considered the most appropriate place for students with exceptionalities. However, mainstreaming students with disabilities into regular public schools exemplified this new stage and belief. 
Table 2. Statistical survey of special education schools (institute) in 1991/1992

\begin{tabular}{|l|l|l|l|l|l|l|}
\hline Type of Institute & Disability & $\begin{array}{l}\text { No. of } \\
\text { Institutes }\end{array}$ & Classes & Students & $\begin{array}{l}\text { Teaching } \\
\text { Staff }\end{array}$ & Administration \\
\hline Al Nour & Blind & 10 & 126 & 625 & 264 & 60 \\
\hline Al Amal & Deaf & 23 & 312 & 2855 & 606 & 157 \\
\hline $\begin{array}{l}\text { intellectual } \\
\text { disabilities }\end{array}$ & $\begin{array}{l}\text { intellectually } \\
\text { disabled }\end{array}$ & 14 & 233 & 2250 & 476 & 127 \\
\hline Grand Total & $\mathbf{4 7}$ & $\mathbf{6 7 1}$ & $\mathbf{5 7 3 0}$ & $\mathbf{1 2 4 6}$ & $\mathbf{3 4 4}$ \\
\hline
\end{tabular}

Note: (1) Al Nour = Light, (2) Al Amal = Hope

Source: (Ministry of Education [12]. Special Education. Riyadh, Saudi Arabia: General administration of Special Education)

\section{The expansion}

The field of special education in Saudi Arabia experienced a rapid progress in the 1995 and above. Along with quantitative growth, a new dimension materialized that could be described as qualitative [14]. A focus on various service delivery models and the mainstreaming of non-traditional disability categories are the most distinguished characteristics of this stage of development.

Mainstreaming in Saudi Arabia means "educating children with special educational needs in regular education schools and providing them with special education services" (p.8) [17]. It is implemented by two types, partial mainstreaming and full mainstreaming. The partial mainstreaming is selfcontained classes in regular public schools, while the full mainstreaming is accomplished through special education support programs, which include resource room programs, itinerant teacher programs, and teacher-consultant programs [16].

Special education provision is no longer limited to the three traditional categories (blind, deaf, intellectually disabled students). However, the mainstreaming programs in Saudi Arabia focus on different categories of disability by targeting two groups of students. The first group includes gifted, learning disabled, physically disabled, behavioral and emotional disturbed, communication problems, hard of hearing, and low vision. These categories are already in regular schools but without special education services. Thus, mainstreaming programs provide such services. The second group consists categories of blind, deaf, intellectual disabilities, autism that is educated in separate special schools or self-contained classes. These categories need to be mainstreamed into regular schools $[16,18]$.

These new trends in special education have created the opportunity for more students to secure services, shown by the number increase from 5,208 students using services in 1992 to 63,461 students receiving special education services in the year 2015 (see Table 3). However, most of students with disabilities can now receive services in resource rooms and self-contained classrooms, as well as through consultation and itinerary alternatives. Out of services provided for special education, $92 \%$ are provided within the regular school, while only 8 percent are provided in institutions [16].

Table 3. Distribution of Institutes, programs and students in 2014/2015

\begin{tabular}{|l|l|l|}
\hline Disability & $\begin{array}{l}\text { No. of Institutes \& } \\
\text { Programs }\end{array}$ & No. of Students \\
\hline Hearing impairment & 586 & 6881 \\
\hline Visual impairment & 363 & 3214 \\
\hline Intellectual disabilities & 1101 & 20576 \\
\hline Autism & 220 & 1464 \\
\hline Multiple disabilities & 58 & 490 \\
\hline Learning disabilities & 2393 & 26225 \\
\hline hyperactivity & 30 & 81 \\
\hline Physical and health disabilities & 90 & 4530 \\
\hline Grand Total & 4796 & 63461 \\
\hline
\end{tabular}

Source: (Adapted from Ministry of Education [19]. A statistical brief of Special Education programs and institutes for the academic year 2014/2015. Riyadh, Saudi Arabia: General Administration of Special Education) 
Coinciding with a notable increase in the prevalence of students with special needs receiving special education services in regular schools, there has also been a growing effort by the Ministry of Education to involve parents in the education of their children with disabilities. A number of legislations were enacted to give parents the right to be included as partners in the decision-making of educational programs of their children [17].

\section{The governance of special education}

As mentioned above, the Ministry of Education established the administration of special education in 1962, which was considered a critical step in serving students with disabilities. However, to handle this additional task, the administration of special education established a department for each type of disability, in addition to departments for Programs for Gifted and Talented Children, Students' Accommodations, Research and Development, Public Relations, Educational Awareness, and Administrative Affairs. Moreover, the number of special education departments housed in regular education districts throughout the kingdom is increasing.

\section{Legislation}

Since the 1975 (the Education for all Handicapped Children Act), mainstreaming has become an important trend for educating students with disabilities in many countries. Saudi Arabia is one of those countries that implemented mainstreaming for educating students with disabilities. However, the Provision Code for individuals with disabilities in Saudi Arabia was issued in 2000. This law guarantees the rights for students with disabilities a free and appropriate education. Moreover, the rules and regulation that reaffirms the regular schools are the natural place for students with disabilities was issued in 2002 [17]. In 2008, Saudi Arabia signed and ratified the convention on the rights of persons with disabilities and its Protocol. Article 24 of the convention calls to ensure an inclusive education [16].

\section{Teacher education in special education}

The field of special education in its early stage faced shortage in trained teachers. Most of special education teachers and administrators were nonSaudi. For example, in the year of $1974-75,44.3 \%$ of special education teachers and $58.6 \%$ of special education administrators were non-Saudi [20]. However, the situation has changed and the teacher education in special education was recognized by establishing the Department of Special Education at
King Saud University. This specialized department, with the majority of faculty members being those who graduated from schools in the USA and England, played a significant role in the development of Teacher education in the field of special education in the Kingdom. Now, there are more than 11 Special Education Departments in Saudi Universities.

\section{Curriculum and educational levels}

The special education curriculum is the same as the regular education curriculum, but with special modification and accommodation based on the type of disability. For example, visual impairment books are printed in Braille, while instructional methods and accommodations are provided to students with learning disabilities. Special education schools and programs implement the 3 levels of education division as following: Elementary school 6 years, Middle school 3 years, and High school 3 years.

\section{Prevalence of students with disabilities}

There is no data as to the number of school-age students with disabilities in Saudi Arabia or their distribution over the different disability categories. The only information available involves the number of students with disabilities being served. However, using the estimate suggested by the U.S. Department of Education in 2009 [21], and considering that Saudi students age six to seventeen are estimated at five million $[1,2]$, the number of students who may need special education can be estimated to be 665000 students (see Table 4).

A substantial progress at the dawn of the $90 \mathrm{~s}$ segregated facilities was the main educational placement. With the additional departments, along with the higher number of student involvement, the field of special education in Saudi Arabia proved its success through its growth. However, more efforts are needed to close the gap between the number of students with disabilities who is receiving special education services and the estimated number of school age students with disabilities in the country. This can be accomplished by expanding the mainstreaming programs to all geographic areas to be in each school across the kingdom to serve every student with disability.' 
Table 4. Estimate of students with disabilities by categories in Saudi Arabia

\begin{tabular}{|l|l|l|}
\hline Type of Disability & \% & Estimate \\
\hline Specific learning disabilities & 5.0 & 250000 \\
\hline Speech or language impairments & 2.9 & 145000 \\
\hline Intellectual disability & 1.0 & 50000 \\
\hline Emotional disturbance & 0.9 & 45000 \\
\hline Hearing Impairment & 0.2 & 10000 \\
\hline Visual Impairment & 0.1 & 5000 \\
\hline Orthopedic impairments & 0.1 & 5000 \\
\hline Other health impairments & 1.3 & 65000 \\
\hline Autism & 0.7 & 35000 \\
\hline Traumatic brain injury & 0.1 & 5000 \\
\hline Developmental delay & 0.7 & 35000 \\
\hline Multiple disabilities & 0.3 & 15000 \\
\hline All disabilities & $\mathbf{1 3 . 2}$ & $\mathbf{6 6 5 0 0 0}$ \\
\hline
\end{tabular}

\section{Factors influencing the progress of special education}

The rapid progress of Special Education in Saudi Arabia can be attributed to several factors. The most important of which are:

1. Government Support: The government of Saudi Arabia has paid considerable attention to the education of people with disabilities and those who are gifted. Their support had influenced the general attitude and morale towards these individuals, causing acceptance and support from people and official establishments, such as ministries and schools [16].

2. Specialized Cadre: Special Education in Saudi Arabia used a number of specialists (all U.S. graduates) who were able to plan for its development and expansion. However, most of the teachers and low-level managers are Saudi graduates who received their undergraduate training in Special Education at King Saud University in the leading Special Education department. Specially trained cadre proved instrumental in developing and improving Special Education programs

3. Strategic Planning: The rapid growth of special education can be also attributed to a strategy set by the leaders of Special Education in Saudi Arabia. The most pertinent strategic ideas as stated by [16] are:

A. Urging regular schools to take an active role in the education of exceptional students through consultation, resource rooms, and self-contained classrooms.

B. Developing human resources for special education through teacher preparation programs, conferences, symposiums, and scholarships to other countries that are advanced in Special Education services.

C. Rely on the research findings in improving the quality of special education services and guiding the practices

\section{Conclusion}

The purpose of this paper was to give a historical perspective on special education in Saudi Arabia from its beginning in 1958 to present time. Although there are many private and government establishments that provide services to exceptional children, the focus here is on the efforts of the Ministry of Education for it is the major source of such services.

From a modest start, the field of special education in Saudi Arabia made remarkable progress in a relatively short period of time. This rapid growth was generated by several factors, including government support, specialized cadre, and strategic planning.

The growth of special education is reflected in several faucets. Many non-traditional categories of exceptionality, such as learning disabilities, gifted/talented, and autism are now included in special education services. In addition, the continuum of service alternatives is becoming an option for placement instead of the institution-only model. Finally, the services are reaching remote areas and small towns and are not restricted to major cities, as was the case a two decades ago.

The experience of the Ministry of Education in Saudi Arabia, although far from being complete, is a good example of what developing countries may need and can do to provide specialized services for their children with exceptional needs.

\section{References}


[1] Ministry of Education. (2014) 'A Statistical Brief on Education in Academic Year of 2014-2015'; http://www.Moe.gov.sa (5 June 2015).

[2] Albelad Newspaper. (Dec. 1, 2012) ‘5,000,000 Students Started Their School Year Today'.

[3] Nations Encyclopedia. (2015) 'Asia and the Pacific: Saudi Arabia';http://www.nationsencyclopedia.com/ economies/Asia-and-the-Pacific/Saudi-Arabia.html \#ixzz3bnAKdxG3 (1 June 2015).

[4] CIA Word Fact Book. 'The Word Fact Book'; https://www.cia.gov/library/publication/the-wordfacebook/index.html (9 June 2015).

[5] UNESCO Institute for Statistics. (2014) 'UIS Statistics in Brief'; http://Stats.uis.unesco.org/unesco/TableViewer/ document.aspx? Reported=198\&IF_Language=eng $(9$ June 2015).

[6] United Nation. 'Convention and Optional Protocol Signature and Ratifications'; http://www.un.org/ disabilities/countries.asp? (9 June 2015).

[7] Nyrop, R. F. (1984) Saudi Arabia, a Country Study, United States Government Printing Office, Washington, D.C.

[8] The Royal Embassy of Saudi Arabia, Washington, DC. (2015) 'About Saudi Arabia'; https://www.saudiembassy. net/about/country-information/energy/oil.as (20 July 2015).

[9] Wikipedia. (2014) 'Saudi Arabia'; en.wikipedia.org/ wiki/Saudi_Arabia (2 June 2015).

[10] Long, D. E. (1976) Saudi Arabia, Sage Publications, Beverly Hills, CA.

[11] Central Department of Statistics \& Information, National Statistical Office of Saudi Arabia. (2014) 'Population statistics'; www.cdsi.gov.sa (31 May 2015).

[12] Ministry of Education. (1992) Special Education, General Administration of Special Education, Riyadh, Saudi Arabia.

[13] Ministry of Education. (2001) Guiding Principles for Special Education Institutes and Programs, General Administration of Special Education, Riyadh, Saudi Arabia.

[14] Al-Mousa, N. A. (2008) The Expansion of Special Education in the Kingdom of Saudi Arabia: from Segregation to Mainstreaming, Dar Algalam, Dubai, UAE.

[15] Ministry of Education. (1981) Directory of Special Education in the Kingdom of Saudi Arabia, General Administration of Special Education, Riyadh: Saudi Arabia.

[16] Al-Mousa, N. A. (2010) The Experience of the Kingdom of Saudi Arabia in Mainstreaming Students with Special Educational Needs in Public Schools, The Arab
Bureau of Education for the Gulf States, Riyadh, Saudi Arabia.

[17] Ministry of Education. (2002) The Document of Roles and Regulation for Special Education Institutes and Programs, General administration of Special Education, Riyadh, Saudi Arabia.

[18] Alkashramy, S. (2003) The development of special educational in the Kingdom of Saudi Arabia: A model of autistic programs, a paper work to the Saudian culture week in Jordan, Amman

[19] Ministry of Education. (2015) A Statistical Brief of Special Education Programs and Institutes for the Academic Year 2014/2015, General Administration of Special Education, Riyadh, Saudi Arabia.

[20] Anita, N. (1978) 'Special educational in the Kingdom of Saudi Arabia', Paper presented at the World Congress on Future of Special Education.

[21] Snyder, T. D. and Dillow, S.A. (2013) Digest of Education Statistics 2012, Chapter 2. National Center for Education Statistics, Institute of Education Sciences, U.S. Department of Education, Washington, DC. 